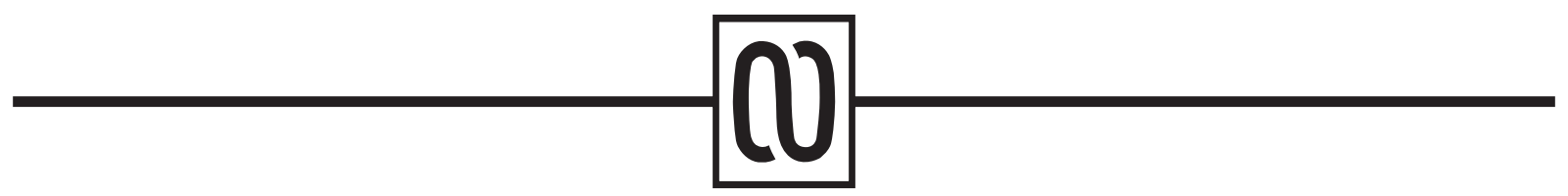

\title{
El cine mexicano y el TLCAN
}

Lucila Hinojosa Córdova*, José Antonio Padrón Machorro*

\section{RESUMEN}

En este trabajo se analizan los efectos que en la producción, circulación y consumo cinematográficos de películas mexicanas han tenido las políticas económicas neoliberales, desregulaciones y apertura del mercado de la industria cinematográfica nacional que se adoptaron desde la firma del Tratado de Libre Comercio de América del Norte (TLCAN) entre México, Estados Unidos y Canadá en 1992, el cual cumplió, en enero de 2017, 25 años de haberse firmado. Se realizó un análisis de la producción a nivel nacional durante el periodo 19902016; de la exhibición a nivel local de la oferta de películas mexicanas en los cines comerciales de Monterrey, México; y del consumo, con base en los indicadores de asistencia e ingreso en taquilla.

Palabras clave: cine mexicano, TLCAN, producción, exhibición, consumo.

El 1 de enero de 2017 se cumplieron 25 años de la firma del Tratado de Libre Comercio de América del Norte (TLCAN o NAFTA), entre México, Estados Unidos y Canadá. En este periodo se ha transformado la mayoría de los procesos productivos y de servicios del país para tratar de incorporarse a la dinámica mundial de la globalización de los mercados, pero con diferentes y asimétricos efectos. Algunos de estos sectores están revisando sus resultados con el propósito de participar en la renegociación que las autoridades de los tres países están organizando, por lo cual es un buen momento para examinar también su impacto en la industria cinematográfica mexicana y, en su caso, evaluar o no su renegociación.

La adopción de políticas económicas neoliberales, como la apertura de los mercados, las privatizaciones de los sectores productivos y de servicios, y las desregulaciones o cambios regulatorios fueron las condiciones estructurales que facilitaron la entrada de México a la dinámica de la globalización, que si bien inició desde finales de la década de 1980 fue en la de 1990 que se reafirmó en el contexto del TLCAN.

\section{ABSTRACT}

This paper analyzes the effects on film production, circulation and consumption of Mexican films of the neoliberal economic policies, deregulation and market opening of the national film industry that have been adopted since the signing of the North American Free Trade Agreement (NAFTA) between Mexico, the United States and Canada in 1992, which celebrated its 25th anniversary in January 2017. An analysis was made of production at the national level during the period 1990-2016; of the local screening of Mexican films in commercial cinemas in Monterrey, Mexico; and of consumption, based on attendance and box-office entry indicators.

Keywords: mexican cinema, NAFTA, production, screening, consumption.

El sector de la industria cinematográfica fue uno de los sectores más afectados por estos cambios. La implicación más seria del TLCAN es que llegó a convertirse en nuestra respuesta básica a la globalización, proporcionando una gran oportunidad para acceder al mercado estadounidense de manera preferencial y de hacernos atractivos a la inversión extranjera, pero al mismo tiempo con el gran desafío de habernos insertado muy rápidamente en un entorno de libre mercado asimétrico, donde tuvimos que competir, de la noche a la mañana, con países y empresas poderosos, sin apoyos de transición como los que operan en otros contextos como el europeo.

Entre los beneficios estarían el aumento en las exportaciones y la inversión extranjera, sin descuidar el mercado interno, al impulsar el mercado nacional y las inversiones mediante acciones de fomento. Desafortunadamente, el TLCAN arrancó sin que México estableciera las condiciones internas para una participación competitiva, al menos en el sector cinematográfico.

\footnotetext{
*Universidad Autónoma de Nuevo León
} 
¿Cuáles han sido las consecuencias que las políticas económicas neoliberales como la apertura de los mercados, desregulaciones y privatizaciones inherentes al TLCAN han tenido en el circuito productivo de la industria del cine mexicano?

La firma de este tratado trajo consigo cambios incluso antes de que entrara en vigor en 1994: caída en la producción, concentración en la distribución y exhibición, disminución en la asistencia y la taquilla (consumo).

Quizá el factor más decisivo de estos cambios fue que a las dos semanas de haberse firmado el TLCAN, en 1992, se promulgó una nueva Ley Federal de Cinematografía que, junto con su reglamento, "legalizaron" lo que luego se vio como una "transformación", y no crisis, del circuito productivo de esta industria.

Los antecedentes de la legislación cinematográfica mexicana se remontan a 1913, cuando se publica el primer ordenamiento en la materia, en 1919 surge el reglamento de la censura cinematográfica, y en 1947 se expide el Reglamento de la Comisión Nacional de Cinematografía. Dos años después, en 1949, se aprueba la Ley de la Industria Cinematográfica, la cual es reformada en 1952. En esta Ley se obligaba a los exhibidores a dar espacio de $50 \%$ de las pantallas a la producción nacional.

Cuando se modificó la Ley de Cine en 1992, se "entregó" la distribución y exhibición a las fuerzas del mercado, léase el oligopolio transnacional que las controla, sin protección alguna para nuestro patrimonio cinematográfico. En su Artículo 19, relativo a la exhibición, se estipuló que la exhibición de películas mexicanas en nuestras pantallas debía ir disminuyendo un porcentaje a partir de 1993, para quedar en $10 \%$ en 1997. Paradójicamente, en el TLCAN quedó asentado en el Anexo I, de la lista de México, que "el treinta por ciento del tiempo anual en pantalla en cada sala, puede ser reservado a las películas producidas por personas mexicanas dentro o fuera del territorio de México". En pocas palabras, el TLCAN resultó más "benévolo" que nuestra propia legislación.

Esta Ley decretada en 1992 ha tenido varias adiciones en 1999, 2002, 2006, 2010 y 2015, pero ninguna ha tenido repercusiones significativas en apoyo a la industria del cine, al contrario, sigue restringiendo la exhibición de películas mexicanas a $10 \%$, contraviniendo el fomento, conservación y difusión de nuestro patrimonio nacional. Fue a partir de entonces que se vino la caída de la producción en rápido descenso, provocando una crisis de la que se ha venido recuperando en la última década.

\section{OBJETIVO DE LA INVESTIGACIÓN}

Este documento forma parte de una línea de investigación que se ha desarrollado desde 1998 a la fecha (Hinojosa 2002, 2003, 2007, 2012, 2016), con el propósito de analizar los efectos que en la producción, circulación y consumo cinematográficos de películas mexicanas han tenido las políticas económicas neoliberales, desregulaciones y apertura del mercado de la industria cinematográfica nacional que se adoptaron desde la firma del TLCAN.

\section{MÉTODO}

El estudio que se ha realizado es no experimental, de tipo mixto, longitudinal y descriptivo, desde una perspectiva global/local. Como técnicas de estudio se han utilizado la investigación documental, el análisis de contenido, la encuesta y la entrevista. Se revisan, entre otros documentos, la normativa vigente y sus actualizaciones, investigaciones recientes y documentos oficiales como los informes del Instituto Mexicano de Cinematografía (Imcine) en cuanto a la producción, exhibición y consumo de películas, para contar con un marco de referencia nacional con el cual contrastar la evidencia empírica local obtenida del análisis de la oferta que se exhibe en los cines comerciales de Monterrey, aplicando el análisis de contenido a las carteleras cinematográficas publicadas en el periódico El Norte, el de mayor circulación en la ciudad, con un tamaño de muestra de dos semanas compuestas por año durante el periodo 1992-2015, utilizando el intervalo como proceso de selección para obtener muestras representativas de cada año, tamaño de muestra válido para un análisis de contenido de mensajes difundidos en los medios de comunicación como la prensa (Riffe, Aust y Lacy citados por Lozano, 1994). Dos semanas compuestas por año son 14 días de cada año, donde el proceso de selección por intervalo $(365 / 14)$ permite obtener una muestra representativa de enero a diciembre de cada año.

Para la encuesta se utiliza un muestreo no probabilístico, aplicando un cuestionario a la salida de los cines a personas de ambos sexos, mayores de 18 años (sujetos voluntarios), que hayan asistido a una de las salas a ver una película mexicana. El tamaño de la muestra es aproximadamente de 400 a 600 personas por año. Las preguntas del cuestionario versan acerca de su percepción, modos de ver y frecuencia de asistencia a ver películas mexicanas en las salas de cine. 
Las entrevistas se han realizado a especialistas en el tema y cineastas. La hipótesis de trabajo de inicio era que tanto la apertura del mercado y la desregulación, así como las privatizaciones en el sector no tenían un impacto muy favorable en la producción y circulación de películas mexicanas en el circuito de salas comerciales del país en general, y de Monterrey en particular; sin embargo, las pocas películas mexicanas producidas en este periodo tenían un consumo y recepción favorables por parte de los espectadores que asisten a ver películas mexicanas en los cines comerciales de su área metropolitana.

Por cuestión de espacio, en este artículo se presentan resultados parciales de la investigación.

\section{RESULTADOS Y DISCUSIÓN}

En las dos décadas posteriores a la firma del TLCAN (1992), el cine mexicano pasó por una serie de crisis y transformaciones debidas en parte a las desigualdades que se observaron en los flujos de intercambio comercial internacionales como el de los productos audiovisuales, en específico el de películas cinematográficas. Un control oligopólico de las empresas transnacionales distribuidoras de películas, una legislación inequitativa para el sector, aun y cuando en los últimos años se han implementado algunos estímulos fiscales en apoyo a la producción, y una ausencia de políticas culturales de promoción y fomento para el desarrollo de esta industria, propiciaron que la década de 1990 fuera la de mayor abatimiento de la producción fílmica.

Desde 1990 se empezó a observar un declive en la producción con respecto a la de años anteriores; ese año se produjeron 75 películas, de las cuales se estrenaron 74 en las salas de cine del país; en ese entonces México contaba con 1,896 salas de cine comercial, es decir, $31 \%$ de la cantidad con las que ahora contamos $(6,225)$, pero a las que todavía asistieron 197 millones de espectadores, cuando la población era de 80.08 millones de habitantes de acuerdo a las estadísticas del Inegi (lo que promediaba 2.4 de asistencia/habitante) y el precio del boleto en taquilla era parte de la canasta básica. Actualmente, si bien la producción ha ido en crecimiento, y con todo y que ahora somos más y la industria en conjunto ha mejorado, todavía no alcanzamos esos niveles de proporción entre la producción y exhibición y la asistencia a las salas de cine que se tenían antes del TLCAN.
Tabla I. Películas mexicanas producidas, número de salas y número de espectadores de 1993 a 2003 en México

\begin{tabular}{|c|c|c|c|}
\hline Año & $\begin{array}{c}\text { No. de } \\
\text { películas } \\
\text { mexicanas } \\
\text { producidas }\end{array}$ & $\begin{array}{c}\text { No. de } \\
\text { salas }\end{array}$ & $\begin{array}{c}\text { Millones de } \\
\text { espectadores }\end{array}$ \\
\hline 1990 & 75 & 1896 & 197 \\
\hline 1993 & 49 & 1415 & 103 \\
\hline 1994 & 28 & 1434 & 82 \\
\hline 1995 & 17 & 1495 & 62 \\
\hline 1996 & 16 & 1639 & 80 \\
\hline 1997 & 9 & 1642 & 95 \\
\hline 1998 & 11 & 1760 & 104 \\
\hline 1999 & 19 & 1979 & 120 \\
\hline 2000 & 28 & 2117 & 130 \\
\hline 2001 & 21 & 2579 & 139 \\
\hline 2002 & 14 & 2823 & 152 \\
\hline 2003 & 29 & 2860 & 137 \\
\hline
\end{tabular}

Fuente: Elaboración propia con información del Imcine.

$\mathrm{Al}$ año siguiente de haberse firmado el TLCAN, en 1993, y a un año de entrar en vigor la nueva Ley Federal de Cinematografía, sólo se produjeron 49 películas. Las salas de cine también disminuyeron de 1,896 a 1,415, es decir, la producción se redujo $35 \%$ en un año y las salas de cine $26 \%$. La asistencia fue de 103 millones de espectadores, 94 millones menos que el año anterior, cayó $48 \%$. La crisis había comenzado.

A partir de 1994 el número de salas de cine fue decreciendo y el número de espectadores fue disminuyendo hasta 62 millones en 1995, el peor año de la taquilla para el cine mexicano. Es a partir de 1996 que se empieza a observar un crecimiento débil, pero sostenido, en el número de salas y en la vuelta de los espectadores, pero no así en la producción, la que tuvo un comportamiento muy fluctuante hasta 2006, cuando se empieza a observar un crecimiento sostenido.

En 1997, ante la crisis de la industria, el gobierno federal implementó dos estímulos para la producción: el Fondo para la Producción Cinematográfica de Calidad (Foprocine) y el Fondo de Inversión y Estímulos al Cine (Fidecine), que aún y cuando la comunidad cinematográfica se dividió con algunos a favor y otros en contra, desde entonces han funcionado apoyando la producción. 
Otra medida importante para la recaudación fue la aprobación del artículo 189 de la Ley del Impuesto Sobre la Renta (ISR), con la que se creó un estímulo fiscal, el Eficen, que permite acreditar 10\% del pago anual del ISR a los contribuyentes que inviertan en la producción cinematográfica, lo que ha permitido obtener recursos extraordinarios hasta por 500 millones de pesos anuales. Esta medida ha permitido impulsar la producción de películas mexicanas en el corto y mediano plazo, de tal forma que, en los últimos seis años, la producción de largometrajes nacionales se ha venido incrementado de manera sostenida gracias, en su mayor parte, a estos apoyos federales y a que los cineastas e inversionistas le están apostando al cine mexicano mediante nuevos modelos de negocio que les resultan rentables al atraer al gran público fiel a su cine.

En 2016, de acuerdo al Anuario Estadístico de Cine Mexicano 2016, la producción cinematográfica alcanzó 162 películas, la más alta en la historia del cine nacional, superando, incluso, la Época de oro, de las cuales se estrenaron 90; la infraestructura de exhibición cuenta con 6,225 pantallas de cine distribuidas en 698 complejos cinematográficos en todo el país; la asistencia fue de 321 millones cuando ahora somos 123 millones de habitantes, es decir, el índice promedio de asistencia fue de casi dos por habitante, de estos asistentes, 30.5 millones vieron películas mexicanas; estamos alcanzando los mismos indicadores que teníamos antes del TLCAN, menos en la exhibición; nuestros cineastas están teniendo grandes éxitos tanto en el país como en el extranjero, produciendo películas nacionales e internacionales que están atrayendo a grandes públicos y son reconocidos en festivales y premiaciones, y el país se ha mantenido en la categoría de productor mediano de acuerdo a los estándares de la UNESCO.

El volumen alcanzado, se menciona en el Anuario, posiciona a México entre los 20 países con mayor número de películas producidas anualmente en el mundo y como el principal productor en Latinoamérica.

El cine mexicano se recupera, pero no todo ha sido favorable en esta transformación. La exhibición de películas nacionales, por desgracia, sigue siendo la tarea pendiente, ya que no ha tenido los mismos incentivos que la producción. Si bien en los últimos años se ha incrementado el número de estrenos en pantalla, las cifras no llegan a la cantidad de estrenos que se tenían antes de los cambios en la legislación, los cuales se dieron en paralelo a la entrada del TLCAN, estrenos que eran más proporcionales a la producción, favoreciendo ahora más a las películas extranjeras, básicamente estadounidenses.
Mencionamos que la asistencia promedio anual por habitante fue de dos en 2016, mayor que en otros países de Latinoamérica y Europa. Aun y cuando en 2015 se pusieron en marcha tres plataformas digitales bajo demanda con participación pública, Cinema México Digital, FilminLatino y Pantalla CACI, las salas de cine continúan siendo uno de los principales contactos que tiene el público mexicano con un filme, pese a la competencia que representan las tecnologías de la información y comunicación de bajo costo y variada oferta audiovisual, y al costo del boleto en taquilla que se incrementa cada año en desproporción al incremento en el salario mínimo.

Tabla II. El cine mexicano en números (2013-2016).

\begin{tabular}{|l|l|l|l|l|}
\hline & $\mathbf{2 0 1 3}$ & $\mathbf{2 0 1 4}$ & $\mathbf{2 0 1 5}$ & $\mathbf{2 0 1 6}$ \\
\hline $\begin{array}{l}\text { Pantallas } \\
\text { cinematográficas }\end{array}$ & 5,547 & 5,678 & 5,977 & 6,225 \\
\hline $\begin{array}{l}\text { Películas } \\
\text { extranjeras } \\
\text { estrenadas }\end{array}$ & 364 & 330 & 334 & 317 \\
\hline Asistencia total* & 248 & 240 & 286 & 321 \\
\hline $\begin{array}{l}\text { Películas } \\
\text { mexicanas } \\
\text { estrenadas }\end{array}$ & 101 & 68 & 80 & 90 \\
\hline $\begin{array}{l}\text { Asistencia a ver } \\
\text { películas } \\
\text { mexicanas* }\end{array}$ & 30.1 & 24 & 17.5 & 30.5 \\
\hline $\begin{array}{l}\text { Ingresos en } \\
\text { taquilla** }\end{array}$ & $\begin{array}{l}11,86 \\
0\end{array}$ & 11,237 & 13,334 & 14,808 \\
\hline
\end{tabular}

Fuente: Elaboración propia con datos de los anuarios del Imcine. (*) Millones de personas. (**) Millones de pesos.

Si bien la transformación tecnológica promueve la expansión del consumo y las películas se pueden ahora ver por diversas plataformas digitales, en un país en el que $59.5 \%$ de la población no tiene acceso a las TIC (usuarios de 6 años o más) como es el caso de México (Endutih, 2016), procurar las salidas de difusión a través del circuito de salas para llegar al gran público se vuelve un asunto no sólo de política cultural, sino de política pública. El acceso a los bienes culturales es un derecho de los ciudadanos, de acuerdo a la UNESCO.

En la última década ha sido significativo el crecimiento del número de salas de cine, pero no la oferta $\mathrm{y}$ diversificación de las películas que se exhiben.

En un análisis de la oferta cinematográfica en las salas de cine de Monterrey, como ejemplo de la oferta a nivel nacional, mediante el análisis de contenido de las carteleras publicadas en el periódico El Norte, cuando apenas se firmó el TLCAN, todavía no se había expan- 
dido el concepto de "complejos multiplex" de los cines y apenas se había liberado el precio del boleto en taquilla, los precios eran todavía homogéneos y al alcance de las clases populares. En 1992, en las 77 salas de cine que en promedio daban función por día en Monterrey, se exhibían todavía 32 películas diferentes; a 2015, con 448 salas de cine que dan función en promedio por día, se exhibieron sólo 24 .

Durante el periodo de estudio se han realizado algunas encuestas en los cines de Monterrey, México. Después de la Ciudad de México, Monterrey y Guadalajara son las principales plazas de ingreso de taquilla. En el instrumento se les preguntaba por la frecuencia de asistencia a ver películas nacionales y su percepción sobre éstas, encontrando que, a pesar de la escasez de oferta en los cines en este periodo (2001-2012), el público asistía a ver las pocas que se exhibían.

Las muestras eran en promedio de alrededor de 400600 espectadores. A la pregunta de si habían asistido a ver películas mexicanas en los últimos tres meses, 56\% respondió que sí en 2001; en 2002, 73.5\%; en 2006, $51 \%$; en 2008, 65\%, y en 2010, 53\% (Hinojosa, 2012).

Con todo y que el precio del boleto en taquilla se ha venido incrementando desde su liberación, el precio promedio del boleto es el más bajo del continente y de los más bajos del mundo. El problema es que, al igual que esos precios, el salario mínimo también es de los más raquíticos; México ofrece a los trabajadores los salarios más bajos de la región, catalogados incluso dentro del umbral de la pobreza extrema: a 2016, el salario mínimo era de 80 pesos, cuando la entrada al cine oscilaba entre 45 y 150 pesos, dependiendo de la zona urbana donde se ubicara el complejo cinematográfico. Precisamente estos salarios bajos representan uno de los principales atractivos para las empresas estadounidenses que invierten y emplean trabajadores mexicanos en nuestro país, aprovechando el acuerdo del TLCAN, pero no son suficientes para que las clases populares puedan pagar su boleto de cine.

Si con este salario no se puede cubrir la canasta básica, ir al cine deja de ser una prioridad en una población donde actualmente 64 millones viven en pobreza de acuerdo a sus ingresos.

Por otra parte, el cine no sólo es cultura, también es negocio y contribuye a la economía del país.

La Encuesta Nacional de Ingresos y Gastos de los Hogares de 2015 señaló que los mexicanos gastan 14\% de sus ingresos en actividades de esparcimiento, de las cuales la principal es el cine.
Contrario a lo que piensan algunos economistas y administradores de empresas, "las industrias culturales agregan valor económico y social a naciones e individuos", como lo asegura el economista mexicano Ernesto Piedras (2004), quien también declaró en una entrevista:

Las industrias culturales tienen esta doble naturaleza cultural-económica, y participan en la economía en términos de la creación y de la contribución del empleo al PIB. En el aspecto cuantitativo es una industria muy importante: después de la maquiladora y petrolera, la cultural es la tercera más importante del país si tomamos en cuenta que la turística suma en su participación un porcentaje significativo de lo que aportan los activos culturales (Piedras citado por Alejo, 2012).

En 2014, el PIB de la cultura representó 2.8\% del total nacional; el PIB de la industria cinematográfica creció 5.6\% con respecto al año anterior; el incremento promedio durante el periodo 2008 y 2014 fue de $6.5 \%$ superior al promedio del sector de la cultura e incluso del total del PIB nacional que fue de $2.2 \%$; es decir, el comportamiento del cine ha sido casi tres veces más dinámico que el conjunto de la economía mexicana (Anuario, 2016). El país ocupa también el cuarto lugar a nivel mundial de asistencia a las salas de cine.

\section{CONCLUSIONES}

A la vuelta de 25 años de la firma del TLCAN, la situación del cine mexicano se ve de distinta manera. Estamos hablando de una época de gran crisis que parece se está superando, de una generación de cineastas de los cuales algunos se quedaron en el camino y otros sobrevivieron, de un cambio generacional en los públicos.

Conforme fue pasando el tiempo y se recopilaba evidencia en la investigación, fuimos descubriendo que si bien el modelo económico neoliberal y las privatizaciones que se tuvieron que realizar para incorporarse al TLCAN habían provocado efectos negativos al cine mexicano, el principal factor que restringía su crecimiento y desarrollo era la propia legislación que lo regulaba, la cual se modificó para dejar a la industria a "las libres fuerzas del mercado", ¿quién iba a querer invertir en una producción que por ley luego sólo se iba a exhibir en diez de cada 100 pantallas? En realidad, quienes estaban involucrados en la industria cinematográfica no se habían preparado para su entrada al TL$\mathrm{CAN}$, no los tomaron en cuenta en las negociaciones y cambios regulatorios, y para cuando se dieron cuenta de sus implicaciones, era demasiado tarde. 
Luego de una década de crisis e incertidumbre, a partir de 2006 se empieza a observar que la industria cinematográfica se recupera, y mucho se debe a los estímulos federales que, sin ser cuantiosos, son significativos para muchos cineastas que sin ellos no podrían sacar adelante sus proyectos, además de que están incursionando con nuevos modelos de negocio aprovechando las nuevas tecnologías y realizando asociaciones con inversionistas y productores de otros países, pero también hay que reconocer que existe un público que ha ido en aumento y está apoyando a su cine asistiendo a las salas de exhibición.

Si bien existen determinaciones económicas y políticas de índole internacional, como la preponderancia y control de las distribuidoras transnacionales en la circulación y exhibición de películas, así como de carácter nacional, en lo que se refiere a las restricciones que impone una legislación inequitativa para nuestro cine, hay que voltear a ver a los cineastas que le están apostando a nuestro cine más con voluntad que con apoyo financiero, en aras de impulsar a esta industria y reafirmarla en el mercado global.

Los números hablan, la industria cinematográfica mexicana se recupera, hay que apoyarla e impulsarla. Se vive un momento muy oportuno, no hay que desaprovecharlo. El principal desafío para el cine nacional entonces no es que se renegocie o no el TLCAN, sino que nuestros representantes en el Congreso de la Unión tengan la voluntad política de hacer algo por él para que pueda competir, en igualdad de condiciones, en el mercado cinematográfico mundial. Se debe trabajar primero en una revisión profunda de la legislación para proteger, fomentar y promover nuestro cine nacional. Hacer valer, al menos, ese $30 \%$ en pantalla que se estipula en el TLCAN; no puede ser que un tratado comercial internacional sea más benévolo que nuestra propia legislación.

\section{REFERENCIAS}

Alejo, J. (2012). Al alza, el valor de la cultura. Milenio, Cultura, 23 agosto. Disponible en: http://www.milenio. com/cdb/doc/noticias2011/3604371c5c91951eb11f9c4d$159 \mathrm{~d} 0 \mathrm{e} 0 \mathrm{a}$.

Conaculta. (2016). Anuario Estadístico del Cine Mexicano, CDMX.

Diario Oficial de la Federación. (2015). Ley Federal de Cinematografía, última reforma publicada DOF 17-122015. Cámara de Diputados del H. Congreso de la Unión. Disponible en: http://www.diputados.gob.mx/LeyesBiblio/ pdf/103_171215.pdf
Hinojosa, L. (2002). De lo global a lo local: oferta, consumo y preferencias cinematográficas en Monterrey, N.L. Tesis de Maestría, Universidad Autónoma de Nuevo León.

5. Hinojosa, L. (2003). El cine mexicano. De lo global a lo local. CDMX: Editorial Trillas.

Hinojosa, L. (2007). Una historia local en el horizonte mundial: el cine mexicano en Monterrey. Global Media Journal Mexico. 4(8): 39-60. Disponible en: https://journals.tdl.org/gmjei/index.php/GMJ_EI/article/view/27/27

Hinojosa, L. (2012). Economía política del cine mexicano: oferta y consumo de películas nacionales en Monterrey, México (2001-2010). Revista Eptic. 14(3): 1-21. Disponible en: https://seer.ufs.br/index.php/eptic/article/ view/537/450

Hinojosa, L. (2013). Cine transnacional y espectadores globales. En L. Hinojosa, E. de la Vega y T. Ruiz (coords.). El cine en las regiones de México, Monterrey: Editorial UANL: 277-302.

Hinojosa, L. (2016). El cine mexicano en tiempos de acuerdos y tratados internacionales: crisis, transformaciones y continuidades. Chasqui, Revista Latinoamericana de Comunicación. 132: 47-63. Disponible en:http://revistachasqui.org/index.php/chasqui/issue/view/132_2016/showToc

Instituto Nacional de Estadística y Geografía. (2015). Encuesta Nacional de Ingresos y Gastos de los Hogares 2015. Comunicado de Prensa 274/15, Aguascalientes, Ags., 16 de julio. Disponible en: http://www.inegi.org.mx/saladeprensa/boletines/2015/especiales/especiales2015_07_3. pdf

Lozano, J.C. (1994). Hacia la reconsideración del análisis de contenido en la investigación de los mensajes comunicacionales. En C. Cervantes y E. Sánchez (coords.). Investigar la comunicación. propuestas iberoamericanas. Guadalajara, Jal., UdeG:135-157.

Organización de los Estados Americanos (2016). Tratado de Libre Comercio de América del Norte. Sistema de Información sobre Comercio Exterior (SICE). Disponible en: http://www.sice.oas.org/trade/nafta_s/ANEXO1b.asp

Piedras, E. (2004). ¿Cuánto vale la cultura? Contribución económica de las industrias culturales protegidas por el derecho de autor en México, CDMX: Conaculta.12.

Recibido: 19/08/2017

Aceptado: 13/11/2017 